\title{
Melanoma progression is associated with NK cell exhaustion
}

\author{
Ines Pires da Silva ${ }^{1}$, Anne Gallois ${ }^{2}$, Sonia Jimenez-Baranda ${ }^{3}$, Ana Anderson ${ }^{4}$, Vijay Kuchroo ${ }^{4}$, Iman Osman $^{5}$, \\ Nina Bhardwaj ${ }^{2^{*}}$ \\ From Society for Immunotherapy of Cancer 29th Annual Meeting \\ National Harbor, MD, USA. 6-9 November 2014
}

\section{Introduction}

The immunoregulatory protein $\mathrm{T}$ cell immunoglobulinand mucin-domain-containing molecule-3 (Tim-3) contributes towards $\mathrm{T}$ cell exhaustion in several chronic diseases, including melanoma [1]. NK cells from the latter were shown to be functionally impaired/exhausted, as they failed to proliferate, produce cytokines or kill target cells. In addition they down regulated activating receptors (NKG2D and NKp46) and upregulated inhibitory receptors (KIRB1, KIRNKAT2 and Tim-3). Notably Tim3 blockade reversed this exhausted phenotype, implicating this molecule as a major checkpoint inhibitor in advanced melanoma [2]. To further evaluate NK cell phenotype and function as a consequence of progressive melanoma, we monitored NK cells from a large cohort of patients with stage I-IV melanoma tested the association between NK cell phenotype and clinicopathological variables associated with melanoma prognosis. Expression of MICA (NKG2D ligand) and HMGB1 (Tim-3 ligand) in the plasma/sera of our main cohort was also monitored in an independent validation cohort.

\section{Methods}

NK cells were purified from the peripheral blood of melanoma patients. They were evaluated for the expression of activating and inhibitory receptors. Cytotoxicity was measured by Lamp- 1 expression. IFN- $\gamma$ production was measured after $4 \mathrm{~h}$ stimulation with rhIL-12. Proliferation was quantified by CFSE after 6 days in the presence of rhIL-2. MICA and HMGB1 expression on patients' plasma/sera was measured by ELISA. Event-time distributions were estimated with the use of the Kaplan-Meier method. Two tailed t-test unpaired was used to compare samples from different stages.

\section{Results}

NK cells gradually develop a phenotypic and functional profile consistent with progressive exhaustion, from stage I to stage IV characterized by: 1) up-regulation of inhibitory receptors (Tim-3, KIRB1 and KIRNKAT2); 2) downregulation of activating receptors (NKG2D and NKp46); 3) loss of IFN- $\gamma$ production, proliferation and cytotoxicity. Interestingly, the expression of Tim-3 is higher, while the cytotoxicy and IFN $-\Upsilon$ production is reduced in patients with melanomas thicker than $1 \mathrm{~mm}$. Moreover, higher expression of Tim-3 and KIRB1, and a lower cytotoxic ability and T-bet expression is associated with local or distant metastases. Higher expression of MICA in the plasma was associated with worse prognosis, as was validated in an independent cohort (Figure 1).

\section{Conclusions}

These data demonstrate that NK cells become progressively exhausted in the context of melanoma progression and that Tim-3 blockade possibly earlier in disease may have some benefit on innate immune function. Finally, our data suggest that soluble MICA is a potential prognostic marker which may contribute to the NK cell exhaustion through its interactions with NKG2D.

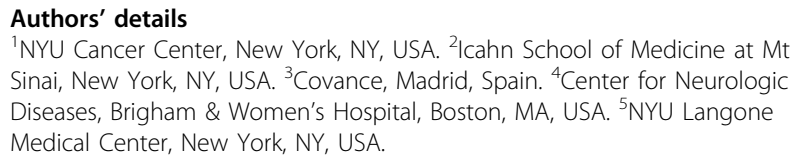

Published: 6 November 2014

${ }^{2}$ Icahn School of Medicine at Mt Sinai, New York, NY, USA

Full list of author information is available at the end of the article 


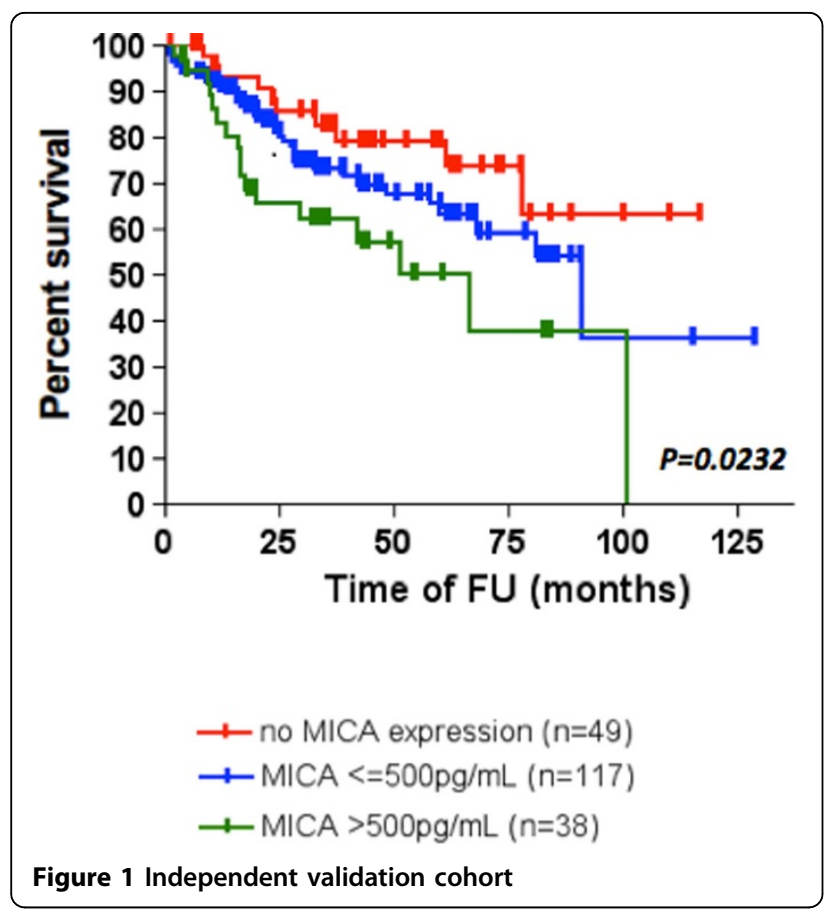

\section{References}

1. Baitsch L, Baumgaertner P, Devevre E, Raghav SK, Legat A, Barba L, et al: Exhaustion of tumor-specific CD8(+) T cells in metastases from melanoma patients. The Journal of clinical investigation 2011, 121(6):2350-60.

2. Ines Pires da Silva, Anne Gallois, Sonja Jimenez Baranda, Shaukat Khan, Ana C Anderson, Vijay K Kuchroo, et al: Reversal of NK cell exhaustion in advanced melanoma by Tim-3 blockade. Cancer Immunol Res 2014, 2(5):410-22.

doi:10.1186/2051-1426-2-S3-O6

Cite this article as: Pires da Silva et al:: Melanoma progression is associated with NK cell exhaustion. Journal for ImmunoTherapy of Cancer 2014 2(Suppl 3):O6.
Submit your next manuscript to BioMed Central and take full advantage of:

- Convenient online submission

- Thorough peer review

- No space constraints or color figure charges

- Immediate publication on acceptance

- Inclusion in PubMed, CAS, Scopus and Google Scholar

- Research which is freely available for redistribution

Submit your manuscript at www.biomedcentral.com/submit 